\title{
Gross and Morphometrical Studies on Mandible of Blackbuck (Antelope cervicapra)
}

\author{
Estudio Macroscópico y Morfométrico de la Mandíbula \\ del Antílope Negro (Antelope cervicapra)
}

Om Prakash Choudhary"; Ishwer Singh*; Sanjay Kumar Bharti*; Khan Idrees Mohd*; Srinivas Sathapathy* \& Meena Mrigesh*

CHOUDHARY, O. P.; SINGH, I.; BHARTI, S. K.; MOHD, K. I.; SATHAPATHY, S. \& MRIGESH, M. Gross and morphometrical studies on mandible of blackbuck (Antelope cervicapra). Int. J. Morphol., 33(2):428-432, 2015.

SUMMARY: The present study has been done on the mandible of blackbuck. The mandible was a paired bone. It was the largest bone of the skull, and it was made up of two halves, which were united with immovable articulation forming mandibular symphysis. It presented for description three surfaces and three borders. The lingual sur-face was smooth and concave. Its symphyseal surface was rough and irregular. The most prominent part of the curve of the ramus formed the angle of the jaw; the part of the ramus between the body and the angle was called horizontal part and carries the lower cheek teeth. The part of the ramus above the angle was termed the vertical part. The vertical part of ramus was non-tooth bearing, expanded vertical part of mandible. Each ramus presented for description two surfaces, two borders and two extremities. The lateral surface was widest at the angle and tapers towards the extremities.

KEY WORDS: Blackbuck; Mandible; Ramus; Teeth.

\section{INTRODUCTION}

The blackbuck (Antilope cervicapra) is an ungulate species of antelope native to the Indian Subcontinent that has been classified as near threatened by IUCN since 2003, as its range has decreased sharply during the 20th century. The blackbuck is protected under Schedule I of the Indian Wildlife Protection Act, 1972. The aim of this study is to investigate mandible of blackbuck, thereby making a contribution in filling the gap of knowledge in this field. As per knowledge, in many vetero-legal cases one fails to identify the bones of this animal and confuse them with those of some other small ruminants. This investigation will be helpful to the field veterinarians as well as zoo veterinarians. Some measurements in the mandibles of blackbuck without any apparent skeletal disorders were analysed. These data are discussed with regard to their application to clinical manoeuvres around the head of the goat such as regional anesthesia during dental extraction. Regional anatomy is an important branch of anatomy directly concerned with the form and relationships of all the organs present in a particular area. Regional anatomy is one of the foundations of clinical and surgical practice because it enables the clinical/surgeon to visualize details of structures relevant to the case at hand (Dyce et al., 1996).

\section{MATERIAL AND METHOD}

The present study was conducted on mandibles of six adult Blackbuck (Antelope cervicapra) of either sex. The permission for the specimen's collection was sought from Deputy Inspector General (WL), Ministry of Environment and Forests (MoEF), New Delhi, India and Principal Chief Conservator of Forest (PCCF), Government of Rajasthan. The skeletons were collected from the Jodhpur zoo after official approvals from Principal Chief Conservator of Forest (PCCF) vide letter no. F,3(02) Tech-II/CCF/2010/714 dated 07.05.2014. The skeletons were dug out from the graveyards located in the premises of Jodhpur zoo. Afterwards, the specimens were processed as per standard technique given by (Choudhary et al., 2013).

The gross study was carried out in Jodhpur zoo under supervision of the zoo personals. Different parameters of mandible were measured and subjected to routine statistical analysis (Snedecor \& Cochran, 1994). This morphometrical study was designed to provide information on some clinically important parameters in the mandible of blackbuck (Figs. 1 and 2). 


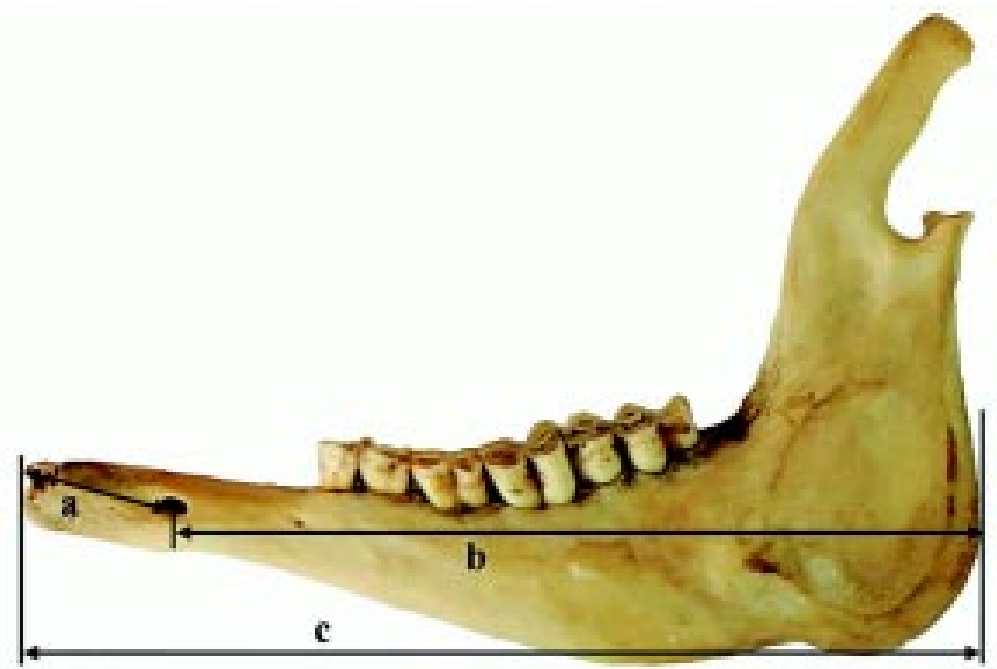

Fig. 1. Medial view of mandible showing measurements; lateral alveolar root to mental foramina (a), Mental foramina to caudal mandibular margin (b), Mandibular length (c).

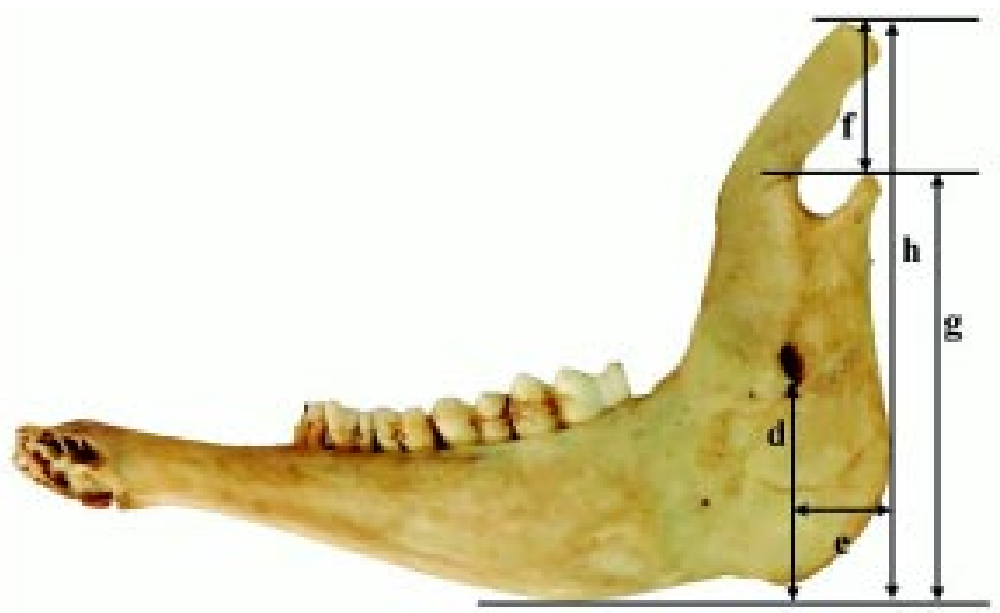

Fig. 2. Lateral view of mandible showing measurements; Mandibular foramen to base of mandible (d), Mandibular foramen to caudal mandibular margin (e), Maximum height of mandible to the condyloid fossa (f), condyloid fossa to base of the mandible (g), Maximum mandibular height (h).

\section{RESULTS}

In present study the mandibular symphysis remained unossified in adult blackbuck. The horizontal part of ramus (Fig. 1) of the mandible was slightly curved, when it was located on a flat surface, it did not touch the surface at both ends. The incisive parts of the body remain lifted from the ground. The body in its alveolar margin presented three incisor teeth and one canine tooth on each side. The molar part of the body presented alveoli for six cheek teeth (three premolar teeth and three molar teeth (Fig. 2). The alveolar margin of the incisive part of the body presented eight alveoli for incisors in blackbuck.
On lateral surface behind the base of canine tooth, only one mental foramen (Figs. 1 and 2) was present. The molar part diverged caudo-laterally from the incisive part to enclose the "V" shaped inter-mandibular space. The mandibular tuberosity was not found during the present study.

The ventral margin of ramus was convex in its length and the alveolar margin was slightly concave in blackbuck.

On the lateral surface of ramus was present a rough area in blackbuck. The articular extremity (caudal extremity) was composed of condylar process and coronoid process (Figs. 1 and 2) with the intervening notch. The coronoid process curved caudally and extended caudodorsally above the condyle to form the highest point of the bone. The head of the condylar process was elongated transversely.

The mandible of blackbuck was found to have a length of $16.53 \pm 0.128 \mathrm{~cm}$ and height of $10.69 \pm 0.024 \mathrm{~cm}$. The distance from the lateral alveolar root to the mental foramen, from the mental foramen to the caudal mandibular margin were $2.45 \pm 0.008$ and $13.43 \pm 0.081 \mathrm{~cm}$ respectively. The width and height of the mental foramen were $0.30 \pm 0.011$ and $0.53 \pm 0.009 \mathrm{~cm}$, respectively (Table I).

The maximum height of mandible to the condyloid fossa and condyloid fossa to base of the mandible were $3.09 \pm 0.008$ and $7.57 \pm 0.024$ $\mathrm{cm}$ respectively. The caudal margin of the mandible to the vertical line downwards form the middle of the mandibular foramen was $1.85 \pm 0.011 \mathrm{~cm}$, while the distance from the mandibular foramen to the base of the mandible was $4.18 \pm 0.014 \mathrm{~cm}$ (Table I). These parameters are of clinical importance as a guide for mandibular nerve block necessary for clinical examination and operations on the alveoli and teeth of the lower jaw. Equivalent figures for the horse and dogs were $3.0 \mathrm{~cm}$ and 1.5 to $2.0 \mathrm{~cm}$ respectively for the distance between the mandible foramen and base of the mandible (Hall et al., 2000). The mental nerve block is indicated in the suturing of the lower lips and for operations on the lower incisors and first 1-2 premolars. The data obtained here of $2.45 \pm 0.008 \mathrm{~cm}$ for the distance between the lateral end of the alveolus 
Table I. The measurements of the mandible of Blackbuck (Description is based on the alphabetical order outlined in Figs. 3 and 4).

\begin{tabular}{llccc}
\hline Sr. No. & Different parameters & Mean value (cm) & S.D. & S.E. \\
\hline a & Lateral alveolar root to mental foramina & 2.45 & 0.02 & 0.008 \\
b & Mental foramina to caudal mandibular border & 13.43 & 0.20 & 0.081 \\
c & Mandibular length & 16.53 & 0.31 & 0.128 \\
d & Mandibular foramen to base of mandible & 4.18 & 0.03 & 0.014 \\
e & Mandibular foramen to caudal mandibular border & 1.85 & 0.02 & 0.011 \\
f & Maximum height of mandible to the condyloid fossa & 3.09 & 0.02 & 0.008 \\
g & Condyloid fossa to base of the mandible & 7.57 & 0.06 & 0.024 \\
h & Maximum mandibular height & 10.69 & 0.05 & 0.024 \\
i & Width of mental foramina & 0.30 & 0.02 & 0.011 \\
j & Height of mental foramina & 0.53 & 0.02 & 0.009 \\
\hline
\end{tabular}

of the incisor tooth to the mental foramen and $0.30 \pm 0.011$ $\mathrm{cm}$ and $0.53 \pm 0.009 \mathrm{~cm}$ for the width and height respectively on the foramen will serve as a guide in the location of the mental nerve for this regional nerve block.

There is no previous information on these parameters in blackbucks, nor in any other domestic animals in India with which comparisons could be made. We therefore believe that the data presented above will form a vital baseline for further work especially comparability and compatibility are now desirable traits as efforts are geared up towards massive improvement in the livestock sector of the international economy.

\section{DISCUSSION}

The mandibular symphysis remained unossified in adult blackbuck which was similar to the findings in ox (Raghavan, 1964), in buffalo (Khatra, 1979) and in dog (Miller et al., 1964); whereas in contrast to this, in camel (Singh, 1984) and horse (Getty, 1975) the mandibular symphysis was completely ossified.

The horizontal part of ramus (Fig. 3) of the mandible was slightly curved, when it was located on a flat surface, it did not touch the surface at both ends. The incisive parts of the body remain lifted from the ground which was in agreement with of Singh \& Patel (1984) in camel, Raghavan in ox; whereas in tiger it was straight and when it was placed on a flat surface, it touched the surface at both ends (Joshi, 2004). The body in its alveolar margin (Fig. 4) presented three incisor teeth and one canine tooth on each side which was similar to the findings in leopard (Kalita et al., 2001) and in tiger (Joshi). The molar part of the body presented alveoli for six cheek teeth (three premolar teeth and three molar teeth). The alveolar margin of the incisive part of the body presented eight alveoli for incisors in blackbuck which was similar to the findings in leopard (Kalita et al.), in horse (Getty) in ox (Raghavan) and in yak (Archana et al., 1998).

On lateral surface behind the base of canine tooth, only one mental foramen (Figs. 3 and 4) was present which was similar to the findings in horse (Getty), in ox (Raghavan), in buffalo (Khatra) and in yak (Archana et al.); whereas in tiger (Joshi), camel (Singh \& Patel) and dog (Miller et al.) there were three mental foramina. However, according to Kalita et al., there were two mental foramina in leopard. The molar part diverged caudo-laterally from the incisive part to enclose the "V" shaped inter-mandibular space which was similar to the findings in ox (Raghavan) in yak (Archana et al.) and in tiger (Joshi).

The mandibular tuberosity was not found during the present study which was similar to the findings in leopard (Kalita et al.), in horse (Getty), in ox (Raghavan), in dog (Miller et al.), and in tiger (Joshi). However, a tubercle has been reported in camel (Singh \& Patel) but it was well developed in yak (Archana et al.).

The ventral margin of ramus was convex in its length which was similar to the findings in dog (Miller et al.), in ox (Raghavan) and in yak (Archana et al.); whereas in tiger (Joshi) ventral margin of mandible was thick, straight and slightly rounded, in leopard (Kalita et al.) and in young horses (Getty) it was thick, rounded and nearly straight, but it became narrower and sharp in older horses (Getty). The alveolar margin was slightly concave in blackbuck which was similar to the findings in leopard (Kalita et al.) however it was straight in camel (Singh \& Patel). The vertical part of ramus was the non-tooth bearing, expanded vertical part of mandible which was similar to the findings in in yak (Archana et al.) and in leopard (Kalita et al.). 


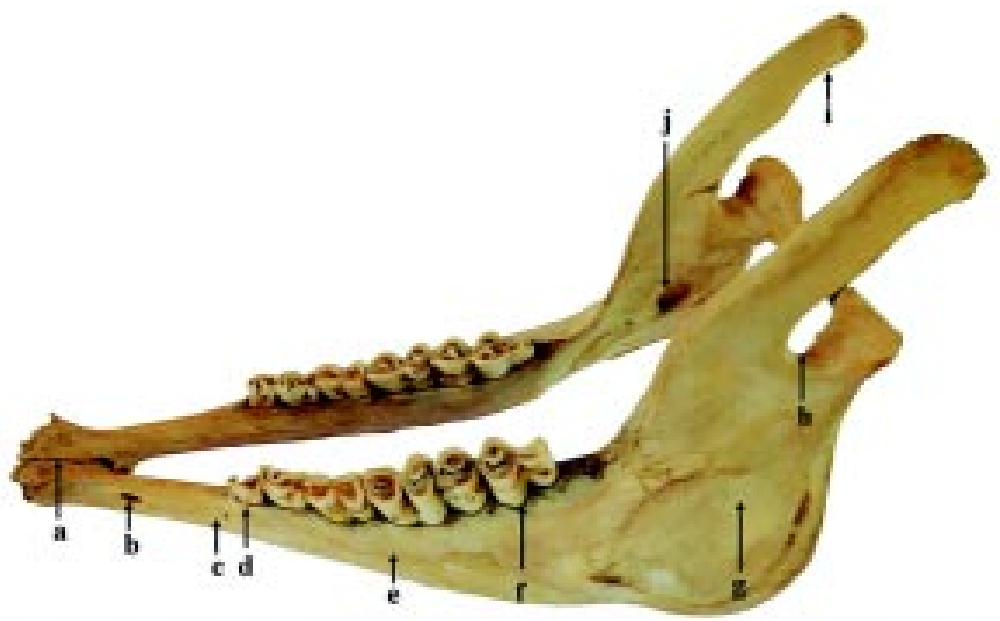

Fig. 3. Dorso-lateral aspect of mandible of female blackbuck showing alveolar sockets for incisors (a), mental foramen (b), anterior margin of ramus (c), first premolar (d), horizontal part of ramus (e), molar (f), posterior margin of ramus $(\mathrm{g})$, vertical part of ramus $(\mathrm{h})$, coronoid process (i), mandibular foramen $(\mathrm{j})$.

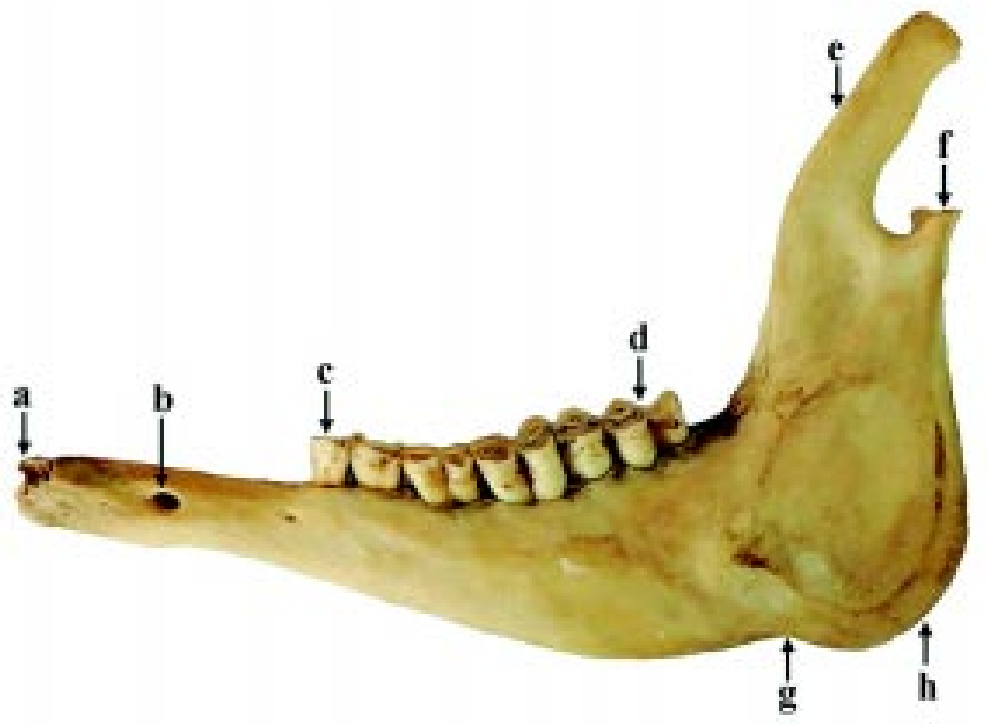

Fig. 4. Lateral view of mandible of female blackbuck showing alveolar sockets for incisors (a), mental foramen (b), first premolar (c), molar (d), coronoid process (e), condylar process (f), ventral groove (g), angle of jaw (h).

On the lateral surface of ramus was present a rough area in blackbuck which was similar to the findings in buffalo (Khatra). There was a big triangular rough fossa in tiger (Joshi). It was concave and roughened in camel (Singh \& Patel), but it did not present rough lines in blackbuck as found in horse (Getty) and in ox (Raghavan).

The articular extremity (caudal extremity) was composed of condylar process and coronoid process (Fig. $3 \& 4$ ) with the intervening notch which was similar to the findings in ox (Raghavan), in yak (Archana et al.) and in leopard (Kalita et al.). The coronoid process curved caudally and extended caudo-dorsally above the condyle to form the highest point of the bone which was similar to the findings in leopard (Kalita et al.) and in yak (Archana et $a l$.). The head of the condylar process was elongated transversely which was similar to the findings in camel (Singh \& Patel), in ox (Raghavan), in buffalo (Khatra) and in tiger (Joshi).

\section{CONCLUSIONS}

The present study has been done on the mandible of blackbuck. The mandible was a paired bone. It was the largest bone of the skull, and it was made up of two halves, which were united with immovable articulation forming mandibular symphysis. It presented for description three surfaces and three margins. All characteristics the mandible of blackbuck was similar to the findings of ruminants (ox, sheep and goat) but disagreements with the findings with camel and horse.

\section{ACKNOWLEDGEMENT}

The authors are grateful to the Ministry of Environment of Forests (MoEF), New Delhi and Jodhpur Zoo for providing facilities and support for carrying out research on bones of blackbuck. Funding was provided by Department of Science and Technology, New Delhi, India as Ph.D. grant (DST-INSPIRE Fellowship) to first author.

CHOUDHARY, O. P.; SINGH, I.; BHARTI, S. K.; MOHD, K. I.; SATHAPATHY, S. \& MRIGESH, M. Estudio macroscópico y morfométrico de la mandíbula del antílope negro (Antelope cervicapra). Int. J. Morphol., 33(2):428-432, 2015.

RESUMEN: Este estudio se llevó a cabo sobre la mandíbula del antílope negro. La mandíbula del antílope negro es un hueso emparejado, corresponde al hueso más grande del cráneo, y está compuesto de dos mitades, unidas por una articulación inmóvil formando la sínfisis mandibular. Se observaron tres superficies y tres márgenes. La superficie lingual era lisa y cóncava y la superficie sinfisial era 
áspera e irregular. La zona más prominente de la curva de la rama formó el ángulo de la mandíbula; el punto de la rama entre el cuerpo y el ángulo se denomina el área horizontal y lleva a los dientes de la mandíbula inferior. El punto de la rama superior al ángulo es conocido como el área vertical. Cada rama presentó para la descripción dos superficies, dos márgenes y dos extremidades. La superficie lateral era más ancha en el ángulo y se extendía hacia las extremidades.

PALABRAS CLAVE: Antílope negro; Mandíbula; Ramus; Dientes.

\section{REFERENCES}

Archana; Sudhakar, L. S.; Shanna, D. N \& Bhardwaj, R. L. Craniometry in yak (Bos grunniens). Ind. J. Vet. Anat., 10:1-8, 1998.

Choudhary, O. P.; Mathur, R.; Joshi, S.; Beniwal, G. \& Dangi, A. Gross and Biometrical studies on carpals of chital (Axis axis). Vet. Pract., 14(1):36-9, 2013.

Dyce, K. M.; Sack, W. O. \& Wensing, C. J. G. Textbook of Veterinary Anatomy. 2nd ed. Philadelphia, W. B. Saunders Co., 1996.

Getty, R. Sisson and Grossman's. The Anatomy of the Domestic Animals. 5th ed. Philadelphia, W. B. Saunders Co., 1975.

Hall, L. W.; Clarke, K. W. \& Trim, C. M. Wright's Veterinary Anaesthesia and Analgesia. $10^{\text {th }}$ ed. London, ELBS and Baillierre Tindall, 2000.

Joshi, H. Gross anatomical studies of the skull of Indian Tiger (Panthera tigris). Doctoral Thesis. Bikaner, College of Veterinary And Animal Science, Rajasthan Agricultural University, 2004.

Kalita, A.; Sarma, M. \& Sarma, K. K. Anatomy of the mandible of Indian leopard. Indian Vet. J., 78(12):1138-40, 2001.

Khatra, G. S. Morphology of the os mandibula of buffalo (Bubalus bubalis). J. Res. Punjab Agric. Univ., 16(1):124-8, 1979.

Miller, M. E.; Christensen, G. C. \& Evans, H. E. Anatomy of the Dog. Philadelphia, W. B. Saunders Co., 1964.

Raghavan, D. Anatomy of ox. New Delhi, Indian Council of Agricultural Research, 1964.

Singh, J. \& Patel, M. R. The osteology of skull of goat. Indian $J$. Vet. Sci. Ani. Husb., 8:80-9, 1984.

Snedecor, G. W. \& Cochran, W. G. Statistical Methods. 8th ed. Ames, Iowa State University Press, singh1994.
Correspondence to:

Dr. Ishwer Singh

Professor and Head

Department of Veterinary Anatomy

College of Veterinary and Animal Science

G.B. Pant University of Agriculture and Technology

Pantnagar-263 145

INDIA

Email:dr.om.choudhary@gmail.com

Singh_iswar@yahoo.co.in

Received: 29-06-2014

Acceptad: 29-01-2015 